\title{
A physiological role for connective tissue growth factor in early wound healing
}

\author{
Maria P Alfaro ${ }^{1}$, Desirae L Deskins ${ }^{1}$, Meredith Wallus ${ }^{1}$, Jayasri DasGupta ${ }^{1}$, Jeffrey M Davidson ${ }^{1,2}$, Lillian B Nanney ${ }^{1}$, \\ Michelle A Guney ${ }^{3}$, Maureen Gannon ${ }^{2,3,4,5}$ and Pampee P Young ${ }^{1,2,6}$
}

Mesenchymal stem cells (MSCs) that overexpress secreted frizzled-related protein 2 (sFRP2) exhibit an enhanced reparative phenotype. The secretomes of sFRP2-overexpressing MSCs and vector control-MSCs were compared through liquid chromatography tandem mass spectrometry. Proteomic profiling revealed that connective tissue growth factor (CTGF; CCN2) was overrepresented in the conditioned media of sFRP2-overexpressing MSCs and MSC-derived CTGF could thus be an important paracrine effector. Subcutaneously implanted, MSC-loaded polyvinyl alcohol (PVA) sponges and stented excisional wounds were used as wound models to study the dynamics of CTGF expression. Granulation tissue generated within the sponges and full-thickness skin wounds showed transient upregulation of CTGF expression by MSCs and fibroblasts, implying a role for this molecule in early tissue repair. Although collagen and COL1A2 mRNA were not increased when recombinant CTGF was administered to sponges during the early phase (day 1-6) of tissue repair, prolonged administration ( $>15$ days) of exogenous CTGF into PVA sponges resulted in fibroblast proliferation and increased deposition of collagen within the experimental granulation tissue. In support of its physiological role, CTGF immunoinhibition during early repair (days $0-7$ ) reduced the quantity, organizational quality and vascularity of experimental granulation tissue in the sponge model. However, CTGF haploinsufficiency was not enough to reduce collagen deposition in excisional wounds. Similar to acute murine wound models, CTGF was transiently present in the early phase of human acute burn wound healing. Together, these results further support a physiological role for CTGF in wound repair and demonstrate that when CTGF expression is confined to early tissue repair, it serves a pro-reparative role. These data also further illustrate the potential of MSC-derived paracrine modulators to enhance tissue repair.

Laboratory Investigation (2013) 93, 81-95; doi:10.1038/labinvest.2012.162; published online 19 November 2012

KEYWORDS: fibrosis; mouse models; repair and regeneration; stem cells; wound healing

Mesenchymal stem cells (MSCs), as effector cells, produce a wide array of cytokines, chemokines, adhesion molecules and other bioactive factors that affect the surrounding immune cells, endothelial cells, cardiomyocytes and fibroblasts, among others. ${ }^{1,2}$ The basis for beneficial outcomes of cell therapy with MSCs has been attributed primarily to the stem cellderived paracrine factors on wounded tissue. ${ }^{1}$ On the basis of initial observations in the MRL/MpJ mouse, our group demonstrated that MSCs expressing high levels of the Wnt modulator, secreted frizzled-related protein 2 (sFRP2-MSCs) promoted better granulation tissue formation in the polyvinyl alcohol (PVA) sponge model and significantly enhanced post infarct myocardial repair, compared with GFP-MSCs. ${ }^{3}$ MSCs with elevated sFRP2 expression also increased functional parameters and decreased pathological cardiac remodeling in a murine myocardial infarct model. ${ }^{3,4}$ Using proteomic profiling, we sought to identify novel agents in the secretome of sFRP2-expressing MSCs and to determine whether they contributed to their reparative phenotype.

Proteomic profiling enables the post-translational identification of key factors involved not only in MSC biology, but also in the repair process. ${ }^{5-7}$ Thus, we applied this technology to gain clues about the nature of secreted factors elaborated by vulnerary MSCs. We identified upregulated connective

\footnotetext{
${ }^{1}$ Departments of Pathology, Microbiology and Immunology, Vanderbilt University Medical Center, Nashville, TN, USA; ${ }^{2}$ The Department of Veterans Affairs Medical Center, Nashville, TN, USA; ${ }^{3}$ Department of Molecular Physiology and Biophysics, Vanderbilt University Medical Center, Nashville, TN, USA; ${ }^{4}$ Department of Medicine, Vanderbilt University Medical Center, Nashville, TN, USA; ${ }^{5}$ Department of Cell and Developmental Biology, Vanderbilt University Medical Center, Nashville, TN, USA and ${ }^{6}$ Department of Internal Medicine, Vanderbilt University Medical Center, Nashville, TN, USA

Correspondence: Dr PP Young, MD, PhD, Departments of Pathology, Microbiology and Immunology, Vanderbilt University School of Medicine, 116121 st Avenue South, C2217A MCN, Nashville, TN 37232, USA.

E-mail: pampee.young@vanderbilt.edu

Received 12 March 2012; revised 27 August 2012; accepted 17 September 2012
} 
tissue growth factor (CTGF also known as CCN2) in the secretome from sFRP2-expressing MSCs.

CTGF is a secreted, matricellular protein belonging to the CCN family of serum-induced immediate-early genes. ${ }^{8}$ This family is rich in cysteines, and its members contain four domains involved in growth factor binding, dimerization, heparin and proteoglycan binding and integrin recognition. ${ }^{9}$ CTGF has been shown to directly bind integrin receptors and heparan sulfate proteoglycans and thus participate in signal transduction events, which lead to the regulation of cell adhesion, migration, proliferation, gene expression, differentiation and survival. ${ }^{10}$ Owing to its ability to modulate the activities of several growth factors and cytokines, including transforming growth factor-beta (TGF$\beta$ ), vascular endothelial growth factor, bone morphogenetic protein, and Wnt proteins, CTGF has the potential to regulate a broad array of biological processes. ${ }^{10}$ As CTGF is present in a wide variety of fibrotic conditions of the skin, kidney, liver, lung and other organs, ${ }^{11-13}$ current thinking in the field suggests that it is a pro-fibrotic molecule; however, its role in wound repair remains less well defined. The results presented herein demonstrate a physiological role for CTGF that is largely restricted to the early wound healing period.

\section{MATERIALS AND METHODS}

\section{Recombinant Protein and Blocking Antibody}

Human CTGF (Gibco PHG0286)

\section{Mice}

All procedures were carried out in accordance with Vanderbilt Institutional Animal Care and Use Committee. The $\mathrm{CTGF}^{\mathrm{lacZ} /+}$ (HET) and $\mathrm{CTGF}^{+/+}$(WT) animals have been described in reference. ${ }^{14}$

\section{Surgical Interventions}

PVA sponge (Medtronics Merocel, $6 \mathrm{~mm}$ ) implantation in ventral subcutaneous pockets and retrieval were performed as previously described. ${ }^{3}$ Two $6 \mathrm{~mm}$ full-thickness excisional wounds were placed on the backs of animals as previously described. ${ }^{15,16}$ In some experiments the MSCs $\left(7.5 \times 10^{5}\right)$ were soak loaded before implantation with or without $25 \mu \mathrm{g}$ of CTGF antibody (R\&D systems, Mab660) or the same amount of IgG (Sigma Aldrich, I5381); both antibodies were reconstituted in PBS. Sponges were injected every day for 7 days with $10 \mu \mathrm{l}$ of $1 \mathrm{mg} / \mathrm{ml}$ anti-CTGF or IgG. Sponges were removed 21 days after implantation and cut in half before preserving in $10 \%$ buffered formalin for $24 \mathrm{~h}$ after which time the sponges were embedded cut side down in paraffin and sectioned for staining. An independent cohort of wild-type $\mathrm{Bl} / 6$ also received excisional wounds and a donut-shaped silicone splint with a $10-\mathrm{mm}$ diameter was centered on the wound and fixed to the skin using an immediate bonding adhesive and interrupted 6-0 nylon sutures. The animals were housed separately after the surgery and were killed at the established temporal intervals.

\section{Cells}

Primary MSCs were generated from pooled bone marrow from three mice as previously described. ${ }^{17}$ For sFRP2 overexpression, MSCs were infected with retrovirus constructs LZRS-sFRP2-GFP (sFRP2-MSCs) or LZRS-GFP (GFP-MSCs) as control as previously described. ${ }^{3}$ GFPpositive cells were sorted using BDFACS Aria (manufacturer) at 2 days after transduction. At least four independent, stable lines were tested. Sorted cells were used for a maximum of five passages.

\section{TCA-Precipitation of Conditioned Media}

Freshly sorted sFRP2-MSCs and GFP-MSCs were plated onto $10 \mathrm{~cm}$ dishes in complete medium and allowed to reach $85 \%$ confluency. Media were removed and the plates were washed with phosphate buffered saline (PBS) before the addition of $10 \mathrm{ml}$ of serum-free medium. The serum-free conditioned media (CM) were collected after $48 \mathrm{~h}$, passed through $0.2 \mu \mathrm{m}$ filter and stored at $-20{ }^{\circ} \mathrm{C}$. Two hundred fifty microliter of trichloroacetic acid (TCA; Sigma T6399, 100\% w/v) was added to $1 \mathrm{ml}$ of CM to precipitate the proteins followed by centrifugation $(14000 \mathrm{~g}$ for $30 \mathrm{~min}$ ). The pellets were washed twice with $500 \mu \mathrm{l}$ of ice cold acetone.

\section{Proteomic Analysis}

Tandem mass spectrometry allows for the interrogation of a large pool of unknown peptides when coupled with fractionation by liquid chromatography (LC). ${ }^{18,19}$ Bioinformatics software such as IDPicker facilitates the identification process of candidate proteins, as it employs decoy database searches to compute the false discovery rate of raw identifications and combines multiple scores to increase confident identifications of proteins from the tryptic peptides without requiring any statistical distribution inference or machine learning. TCA-precipitated protein pellets from the CM were trypsin digested. Strong cation exchange chromatography was used to separate the peptide mixture into fractions, which were then individually analyzed by the Vanderbilt University Mass Spectometry Research Center Proteomics core. Multidimensional LC-tandem mass spectrometry were performed as described ${ }^{20}$ on four biological replicates of CM from both sFRP2-MSCs and GFP-MSCs. Data were analyzed using the bioinformatics software IDPicker v2.1 as previously described. $^{21}$

\section{Immunoblotting}

TCA-precipitated protein pellets from $1 \mathrm{ml}$ of $\mathrm{CM}$ were resuspended in PBS. After BCA protein assay (Pierce) proteins were resolved by SDS/PAGE and transferred to nitrocellulose. Membranes were incubated with primary antibody diluted in $5 \%$ milk-TBST at $4{ }^{\circ} \mathrm{C}$ overnight. A species-specific secondary antibody conjugated to HRP was used and chemiluminescence (PerkinElmer, NEL104) was detected by film. ImageJ version $1.38 \times$ (National Institutes of Health) software was used for densitometry analysis of the appropriate lanes. 
In the absence of a specific and well-accepted protein loading control for secreted protein, we used cell number and total protein for normalization.

\section{RNA Isolation and Quantitative Real-time PCR}

Trizol reagent (Invitrogen) was used to obtain RNA. cDNA was synthesized (iScript, Bio-Rad) and quantitative real-time PCR for CCN2 and COL1A2, was performed in triplicate for each sample (C1000 Thermal Cycler, Bio-Rad; CFX96 Realtime PCR Detection System, Bio-Rad; SsoFastEvaGreen Supermix, Bio-Rad). Reactions were normalized to 18S RNA.

\section{Immunofluorescence}

Sponges and/or excisional wound sections on slides were deparaffinized and blocked with $10 \%$ goat serum for at least $1 \mathrm{~h}$ at room temperature. Tissue sections were incubated in primary antibody to CTGF (NOVUS NB100-724) with 3\% goat serum for at least $2 \mathrm{~h}$ at room temperature at a dilution of 1:100. After washing, secondary antibodies, conjugated to $\mathrm{Cy} 3$, were incubated overnight at $4{ }^{\circ} \mathrm{C}$ at a dilution of 1:500. After washing, coverslips were affixed onto slides using Vectashield Hard Set Mounting Medium with DAPI, which contains $4^{\prime}, 6$-diamindion-2-phenylindone to illuminate nuclei (Vector no. H-1500).

\section{Histology and Morphology}

PVA sponges were bisected and embedded with cut surface down for histology. Masson's trichrome or Ki67 immunostaining for detection of proliferative cells was performed on sponge sections. Five random images from each section were photographed with a CoolSNAP Hq CCD camera (Photometrics). The granulation tissue area for each field was quantified using MetaMorph (Molecular Devices Corporation, Sunnyvale, CA, USA) by outlining tissue and calculating total area per field. The excisional wound tissue was excised along with a 2-mm border. Each wound was bisected and embedded with cut surface down. Masson's trichrome and $\mathrm{H} \& \mathrm{E}$ staining were performed on wound sections. A semi-quantitative, blinded, histopathological scoring of collagen organization was performed on trichrome-stained sections. Scoring scale of 0 was given to sections with sparse collagen with poor collagen organization. A grade of 1 was assigned with a normal collagen content and organization. A grade of 4 was given when collagen content was increased over that expected for a freshly closed wound. A grade 2-3 was given when collagen content and organization ranged between $1-4$.

\section{Inclusion of Human Burn Wounds}

Human burn wounds provided an avenue for confirmation that CTGF dynamics were similar in both mice and humans. Although burn depth, the degree of body surface area involvement, body region, comorbidities and ages of patients are highly variable, the routine excision and discarding of burned skin provides margins containing an ample source of acutely healing human tissue. Burn tissues were collected in accordance with an approved protocol from Vanderbilt's Institutional Review Board. Once patients provided consent for use of discarded tissue, healing burn margins (over regions of partial-thickness injury) were carefully culled from regions of full-thickness burn injury when the dermatome was used to excise rectangular areas of damaged skin in preparation for split-thickness. Such samples were fixed in $10 \%$ neutral buffered formalin, embedded in paraffin, sectioned and subjected to CTGF immunostaining. Our collections included samples from the early stages of repair after burn injury at $3,4,5,6,7(N=3$ each $)$ and 8 days $(N=1)$ and from the later stages of repair at 11, 16, 17 and 20 days $(N=3$ each $)$ after injury. Areas of full-thickness injury were histologically excluded based on examination of hematoxylin and eosin sections.

\section{Statistical Analysis}

The statistical significance between experimental groups and control were determined by Student's $t$-test or analysis of variance followed by Newman-Keuls multiple comparison test, unless otherwise noted, using GraphPad Prism (San Diego, CA, USA). Graphs show Mean \pm s.d. and $P<0.05$ is statistically significant.

\section{RESULTS}

\section{Proteomic Analysis of MSC CM Reveals Important Gene Ontology Changes}

Many groups have speculated that the positive effects of MSCs on wound repair rely on their ability to produce soluble factors that enhance the repair process (reviewed in Gnecchi et $\left.a l^{1}\right)$. Previous work from our lab employed two MSC populations to assess in vivo repair. MSCs were transduced with a control retroviral vector (GFP-MSCs) or with the same vector containing sFRP2 (sFRP2-MSCs). Both our work and work from another laboratory demonstrated increased reparative ability of sFRP2-expressing MSCs. ${ }^{3,4,22}$ sFRP2-MSC-treated wounds displayed increased angiogenesis and granulation tissue formation, ${ }^{3}$ an effect that we hypothesized was secondary to the MSC secretome.

To determine whether secreted proteins were enhancing the reparative ability of the sFRP2-MSCs, the CM of four independent GFP-MSC and sFRP2-MSC isolates were obtained after growth in serum-free media for $48 \mathrm{~h}$. The samples underwent limited proteolysis and the resultant peptides were subjected to bioinformatic analysis as described. This approach enabled us to identify MSC secreted proteins that may mediate the observed effects of sFRP2-expressing MSCs on wound healing.

The cellular compartment localization of the positively identified proteins was assigned using uniProtKB (http:// www.uniprot.org/) and used as a filter for further analysis; only proteins found in the extracellular space were retained. The gene ontology information of the overrepresented proteins in the sFRP2-MSC CM revealed an interesting trend 
towards cellular growth (7\%), differentiation (15\%), protein homeostasis $(22 \%)$, growth factors/signaling $(24 \%)$ and adhesion (32\%). The complete list of sFRP2-MSC overrepresented, secreted proteins and their gene ontology information can be found in the Table 1 .

\section{CTGF is Upregulated in sFRP2-MSCs}

CTGF had the highest relative abundance when comparing the sFRP2-MSC and GFP-MSC secretomes (4.33-fold), although the coverage for this protein was only $19 \%$ with 16 total hits. Table 1 lists all identified proteins with higher expression in sFRP2-MSCs. The CTGF molecule was prominent within the growth factor gene ontology classification. As its presence has been previously documented in wounds, ${ }^{23,24}$ it became an interesting candidate for further validation.

The overexpression of CTGF was supported by quantitative real-time PCR (qRT-PCR) analysis of three different sFRP2-MSC isolates compared with their GFP-MSC counterparts. sFRP2-MSCs had a $14.3 \pm 1.3$-fold increase of CTGF transcripts compared with control cells $(P \leq 0.05$ by Student's $t$-test; Figure 1a). This difference in CTGF mRNA levels was also in concordance with data observed at the protein level. As seen in Figure 1b, immunoblotting of TCA-precipitated sFRP2-MSC CM revealed an overall increase in CTGF compared with GFP-MSC CM (2.6 \pm 0.8 -fold by densitometry). The difference in relative expression at the transcript and secreted protein level could be explained in different ways. First, cytoplasmic fraction was not analyzed. Second, as CTGF binds extracellular matrix proteins, only a portion may be present in the soluble CM. Finally, the translational and post-translational regulation of CTGF is largely uncharacterized, and these processes influence the actual synthetic rate. Regardless, significant upregulation of CTGF in sFRP2-MSCs was consistently confirmed at both the RNA and protein levels, and this matricellular protein may contribute to the vulnerary effects of sFRP2-MSC.

\section{CTGF is Involved in the Early Stages of the Wound Repair Process}

A sustained increase in CTGF within a wound is usually equated with pathological conditions especially fibrosis. ${ }^{1-13}$ However, we observed an increased CTGF production in an MSC population, which have been previously demonstrated to enhance reparative outcomes. ${ }^{3}$ To assess whether CTGF would have an effect in wound repair, we used the PVA sponge model of granulation tissue formation..$^{3,25,26}$ Before implantation, the PVA sponges were soak loaded with either GFP-MSCs $(n=18)$, sFRP2-MSCs $(n=18)$ or saline control $(n=9)$. The sponges were implanted subcutaneously into WT mice. Animals were killed after sponge implantation at day $7(n=3)$, after day $15(n=3)$ and after day $28(n=3)$. RNA was isolated from each sample and qRT-PCR analysis was performed to assess the levels of CTGF. Independent of sponge treatment (ie, even in the absence of MSCs), CTGF transcript levels were the highest at the earliest time point examined (day 7; Figure 1c), and they decreased with time. CTGF protein accumulation, as assessed by indirect immunofluorescence, was evident in both MSCs (identified by GFP co-localization, data not shown) as well as infiltrating host fibroblasts (Figure 1d). These observations correlated with the CTGF transcript levels found in control sponges (data not shown). These data suggested that new granulation tissue formed in the implanted sponges, whether derived entirely from infiltrating host cells (saline control loaded sponges) or those preloaded with MSCs (GFP or sFRP2) demonstrated relatively early expression of CTGF. The regulation of endogenous CTGF expression observed (highest at day 7 and decreasing thereafter) in this subcutaneously implanted model of granulation tissue matches what has been previously reported in the excisional repair of mouse skin. ${ }^{23}$

\section{CTGF Function-Blocking Antibody Given in Early Repair Phase Reduces Quantity and Quality of MSC-derived Experimental Granulation Tissue}

To determine the physiological role and importance of CTGF in MSC-derived granulation tissue, we implanted MSCloaded PVA sponges subcutaneously in mice as described above, admixed with either $25 \mu \mathrm{g}$ of CTGF-blocking antibody or IgG isotype control antibody. Twenty-four hours following implantation, each sponge was injected daily with $10 \mu \mathrm{g}$ of anti-CTGF-blocking antibody or the same amount of IgG control ( $n=4$ in each group) for seven consecutive days. After euthanasia at day 21, sponges were removed for histological analysis. The administration of function-blocking antibodies during the early phase of granulation tissue formation resulted in less granulation tissue over a given cross-sectional area $(31.3 \pm 3.8 \%$ vs $40 \pm 2.3 \%, P<0.05$; Figure $2 \mathrm{~b})$, and the granulation tissue contained less organization (increased fibrinous exudate, pauci-cellular with poor matrix deposition) than those treated with control IgG (Figures 2a top and middle panels and $2 b$ ). Higher magnification evaluation of the granulation tissues observed in sponges treated with blocking CTGF antibody confirmed decreased cellularity and with fewer erythrocyte-containing large vessels than control (Figure 2a middle panels). Indeed, the granulation tissue generated after 7 days of anti-CTGF antibody administration was comparatively less vascularized as determined by density of PECAM-1 immunopositive vascular structures (Figures 2a, bottom panels and 2c). Together, these data demonstrate that physiological expression of CTGF during the early wound healing phase has a positive role in generating mature, wellorganized and vascularized granulation tissue.

\section{Early Exposure to CTGF is not Pro-Fibrotic While Prolonged CTGF Enhances a Proliferative, Collagenous Granulation Tissue in non-Stem Cell-Derived Granulation Tissue}

We evaluated the effect of CTGF on granulation tissue formation independent of MSC influence by testing whether 


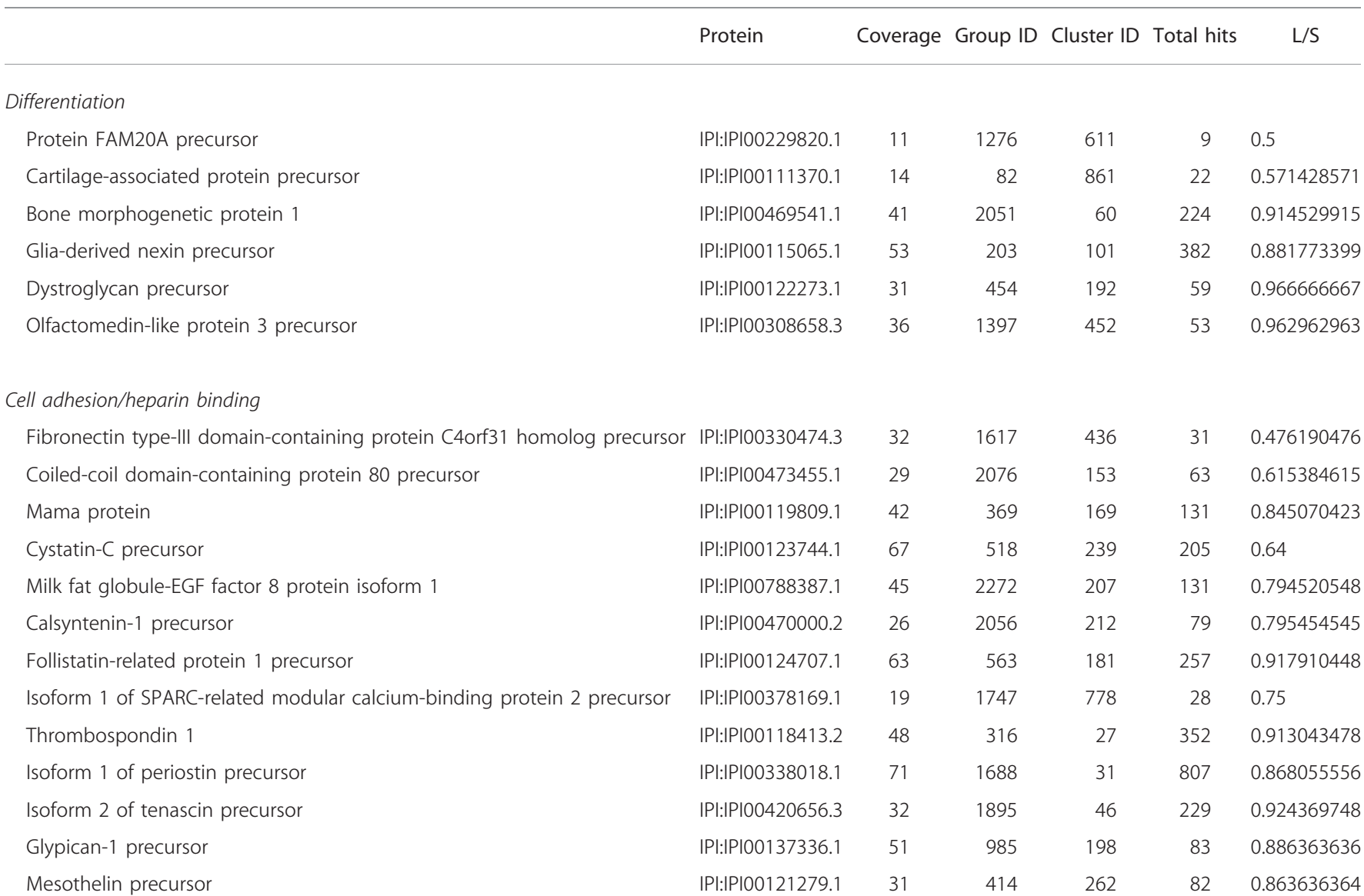

Cell growth

Calreticulin precursor

IPI:IPI00123639.1 $\quad 77 \quad 516$

89

245

0.856060606

Urokinase-type plasminogen activator precursor

IPI:IPI00129102.1 $49 \quad 704$

266

59

0.685714286

Metalloproteinase inhibitor 2 precursor

IPI:IPI00113863.1 $65 \quad 156$

0.904109589

\section{Protein homeostasis}

Lysyl oxidase homolog 1 precursor

IPI:IPI00380136.3 37

IPI:IPI00321190.1 69

IPI:IPI00223231.2 49

IPI:IPI00221402.7 70

IPIIIPI00420710.1 24

IPIIIPI00828662.1 43

IPI:IPI00120176.1 57

IPI:IPI00126050.3 37

IPI:IPI00114209.1 27
1755

1552

1154

1101

1897

2281

385

620

170
294

48

65

97

536

451

116

418

442
57

687

357

196

24

56

567

58

25
0.78125

0.903047091

0.919354839

0.97979798

0.5

0.647058824

0.877483444

0.870967742

0.923076923

Growth factor/signaling

Inhibin beta A chain precursor

Connective tissue growth factor precursor

Plasminogen activator inhibitor 1 precursor

EGF-containing fibulin-like extracellular matrix protein 2 precursor

$\begin{array}{lrrrrr}\text { IPI:IPI00112347.1 } & 31 & 106 & 475 & 32 & 0.391304348 \\ \text { IPI:IPI00322594.3 } & 19 & 1575 & 881 & 16 & 0.230769231 \\ \text { IPI:IPI00131547.1 } & 55 & 815 & 146 & 178 & 0.762376238 \\ \text { IPI:IPI00126055.1 } & 37 & 621 & 415 & 72 & 0.714285714\end{array}$




\begin{tabular}{|c|c|c|c|c|c|c|}
\hline & Protein & Coverage & Group ID & Cluster ID & Total hits & $\mathrm{L} / \mathrm{S}$ \\
\hline Calumenin precursor & IPI:IPI00135186.1 & 65 & 940 & 98 & 147 & 0.8375 \\
\hline Annexin A2 & IPI:IPI00468203.3 & 62 & 2028 & 155 & 181 & 0.865979381 \\
\hline Isoform long of beta-1,4-galactosyltransferase 1 & IPI:IPI00131464.1 & 43 & 813 & 223 & 90 & 0.956521739 \\
\hline Isoform alpha of stromal cell-derived factor 1 precursor & IPI:IPI00108061.3 & 40 & 14 & 1110 & 22 & 0.692307692 \\
\hline
\end{tabular}

Abbreviations: EGF, epidermal growth factor; MSC, mesenchymal stem cell; sFRP2, secreted frizzled-related protein 2.

direct injection of the recombinant CTGF (rCTGF) into sponges in the absence of MSCs could affect wound repair. To determine the effect of the timing of CTGF availability, C57Bl/6 wild-type mice $(n=6)$ were subcutaneously implanted with two sponges in the abdomen. Each sponge received rCTGF injections ( $1 \mu \mathrm{g} /$ sponge in $10 \mu \mathrm{l})$ or saline (adjacent control) every other day for 6, 15 or 28 days. There were six sponges per treatment group. All the animals were killed after 28 days.

No differences were found in the relative amount of granulation tissue area that accumulated in the sponges treated with rCTGF $v s$ saline control for 6 days (top panels, Figure 3a), whereas the sponges that received rCTGF over a 28-day period had much more granulation tissue that had abundant collagen deposition relative to the saline control (bottom panels, Figure 3a). Interestingly, the amount of collagen deposition (trichrome-positive material) in the sponges treated with rCTGF for 6 days appeared to be somewhat less than control, whereas the 28-day-treated sponges demonstrated vastly more collagen deposition than control sponges.

To quantify the effect of rCTGF exposure time on fibrosis, we performed qRT-PCR analysis and measured transcript levels for COL1A2 (Figure 3b). Compared with the saline control, collagen mRNA levels decreased if rCTGF was added through the earlier stages of the wound repair process, reaching a minimum after 15 days of treatment. However, when rCTGF administration was extended to 28 days, the collagen mRNA levels doubled compared with control sponges $(1.9 \pm 1.2$-fold, $P<0.05)$. The proliferation of granulation tissue after prolonged rCTGF exposure regimes was evaluated by Ki67 immunohistochemistry. Figure 3c shows that rCTGF delivered for 28 days significantly increased proliferation $(0.48 \pm 0.23$ vs $0.19 \pm 0.09, P<0.05)$ of fibroblast-type cells within granulation tissue. Together, these results correlate with the idea that prolonged, but not transient, exposure to CTGF promotes an activated fibroblast population. ${ }^{27,28}$ We next used an open murine excisional, stented wound model to examine the pattern of CTGF expression in a physiological model of wound healing. Prior studies have examined CTGF expression in rapidly contracting, fibrotic models. Our plan was to use an animal model that more closely resembled the repair kinetics that are present in humans. The representative $(n=4$ for each time point) panels in Figure 3d illustrate the presence and distribution of CTGF within both epidermis and dermis using indirect immunofluorescence. Although the staining was very weak at day 4 , by day $7-14$, there was robust staining of CTGF. At day 28 CTGF staining was weak to absent. These data suggest that CTGF expression in a model of physiological wound healing follows a time course consistent with the subcutaneous granulation tissue model. CTGF is strongly upregulated after the inflammatory phase and diminished as wound healing nears completion.

\section{CTGF $^{\text {LacZ } /+}$ Mice do Not Exhibit Reduced Healing or Fibrosis in Healing of Excisional Wounds}

We observed a physiological regulation of CTGF during normal wound healing above in both models. On the basis of these data, we would predict that reductions in CTGF in the course of 'normal' (ie, not a fibrotic wound model) should not result in reduced fibrosis and may even impair healing. To test this possibility, we analyzed the wound repair capabilities of haploinsufficient animals $\left(\mathrm{CTGF}^{\mathrm{LacZ} /+}\right.$, HET) with reduced CTGF, and compared them with their wild-type littermates (WT). Constitutive CCN2 deletion results in lethal, perinatal respiratory failure. ${ }^{14,29}$

Full-thickness excisional wounds were created with a biopsy punch ${ }^{15}$ on the backs of WT and HET animals. Animals were sacrificed after 7,10 or 14 days following surgical intervention. The wound repair capabilities of the mice were assessed using a histopathological scoring system that rated: collagen content/organization, granulation tissue maturation, inflammation, epithelialization and vascularization. A portion of each wound was used to isolate total RNA. Real-time RT-PCR analyses for CTGF transcripts were performed for all time points. The wounds obtained from HETs exhibited $15 \pm 5.3 \%, 38 \pm 8.4 \%$ and $43 \pm 4.5 \%$ reduction in CTGF transcripts relative to WT levels at days 7, 10 and 14, respectively, after wounding. All histological evaluations were performed in a blinded fashion, and the scoring is shown in Figure 4. Representative images from this experiment are found in Figure 5. Day 7 HET 

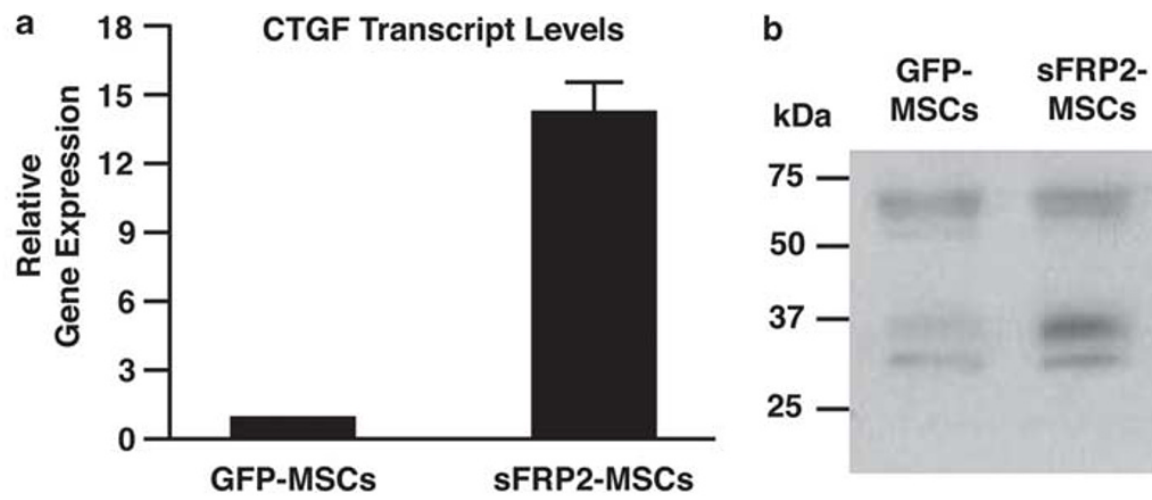

C

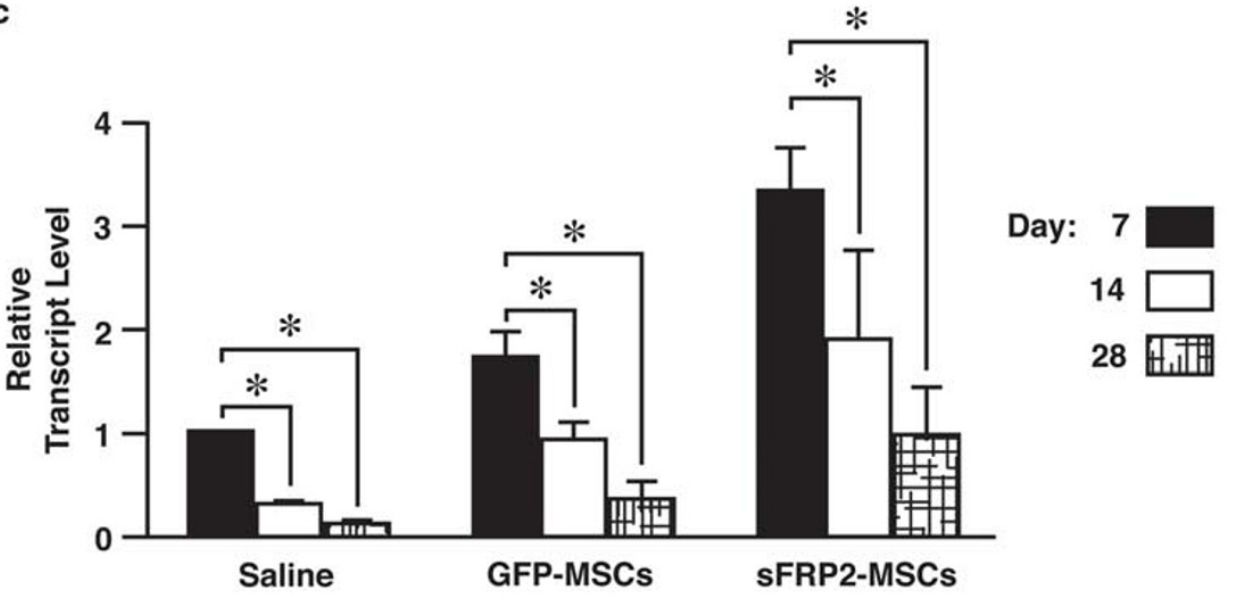

d

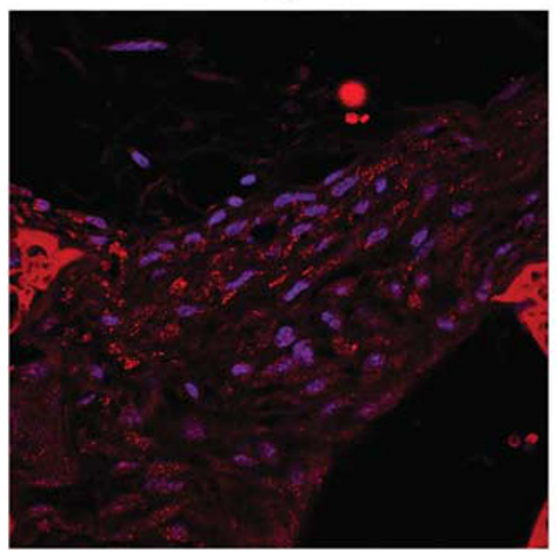

Day 15

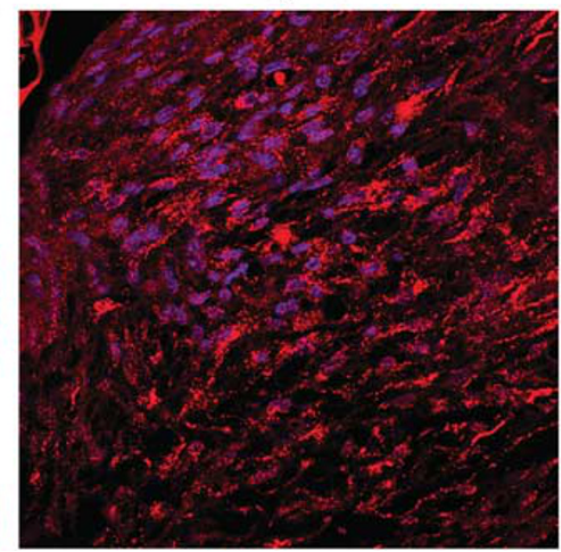

Day 28

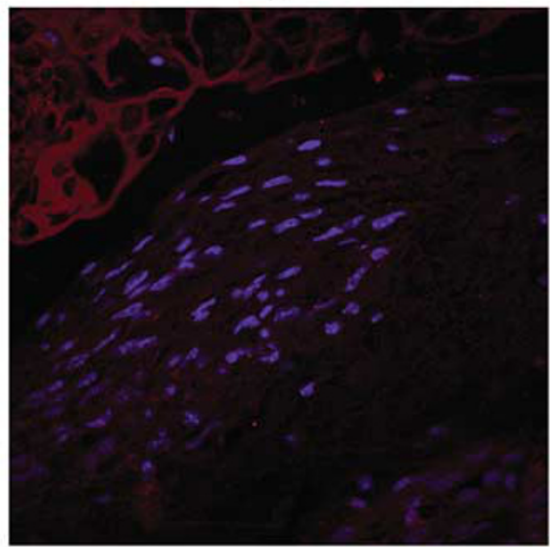

Figure 1 Proteomic analysis reveals connective tissue growth factor (CTGF) upregulation in SFRP2-MSCs and its levels decrease with time within granulation tissue. (a) Quantitative real-time PCR analysis revealed a 14.3 \pm 1.3-fold increase in CTGF transcript levels in SFRP2-MSCs compared with GFP-MSCs, normalized to $18 \mathrm{~S}$ content, $n=3 .{ }^{*} P<0.05$ by Student's $t$-test. (b) Representative blot demonstrating increased CTGF protein in the TCAprecipitated conditioned media (CM) of sFRP2-MSCs. About $20 \mu \mathrm{g}$ of protein; conditioned medium of $1 \times 10^{6}$ cells from each cell type were analyzed. The average intensity increase of the $\sim 37 \mathrm{kDa}$ band is $2.57 \pm 0.8$ as determined by ImageJ analysis of band density, $n=3$. (c) The transcript levels of CTGF within GFP-MSC, SFRP2-MSC- and saline-loaded sponges decrease with time as assessed by qRT-PCR; normalized to $18 \mathrm{~S}$ content, $n=6$ sponges per time point. ${ }^{*} P \leq 0.05$ by one-way ANOVA with Bonferroni post test. (d) Representative immunofluorescent staining with anti-CTGF of granulation tissue generated within SFRP2-MSC-loaded sponges after designated days following implantation.

wounds demonstrated a statistically significant increase in collagen content/organization, granulation tissue and decreased inflammation relative to WT (Figures $4 \mathrm{a}$ and $5 \mathrm{a}$ ). However, there were no differences in the amount of granulation tissue, vascularity, epithelialization at 10 days post injury (Figures $4 \mathrm{~b}$ and $5 \mathrm{~b}$ ). Collagen content and all other parameters were statistically equivalent by day 14 (Figures $4 \mathrm{c}$ and $5 \mathrm{c}$ ). In contrast to our immunoinhibition 
findings, these data indicated that a $\sim 50 \%$ reduction in CTGF transcript levels is not sufficient to alter wound collagen deposition/fibrosis in a normal wound healing situation.

\section{CTGF is Transiently Expressed in Human Burn Wounds}

We explored the corresponding distribution and abundance of CTGF/CCN2 in the acute human wound setting, as loose skinned mammals, such as the mouse, exhibit markedly different scar forming properties. We analyzed the temporal sequence and spatial distribution of representative samples of human partial-thickness $\left(2^{\circ}\right)$ burn wounds at four time intervals post injury (days $3-4$, days 5-6, 7-8 and 11-20) using immunohistochemistry. The representative panels displayed in Figure 6a illustrate the presence and distribution of CTGF- a
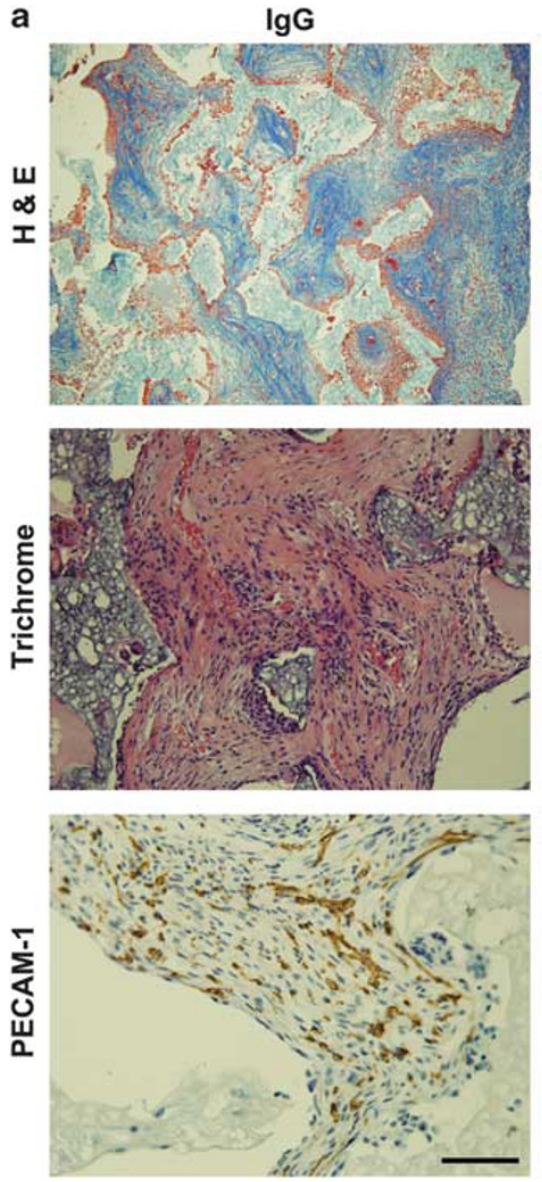
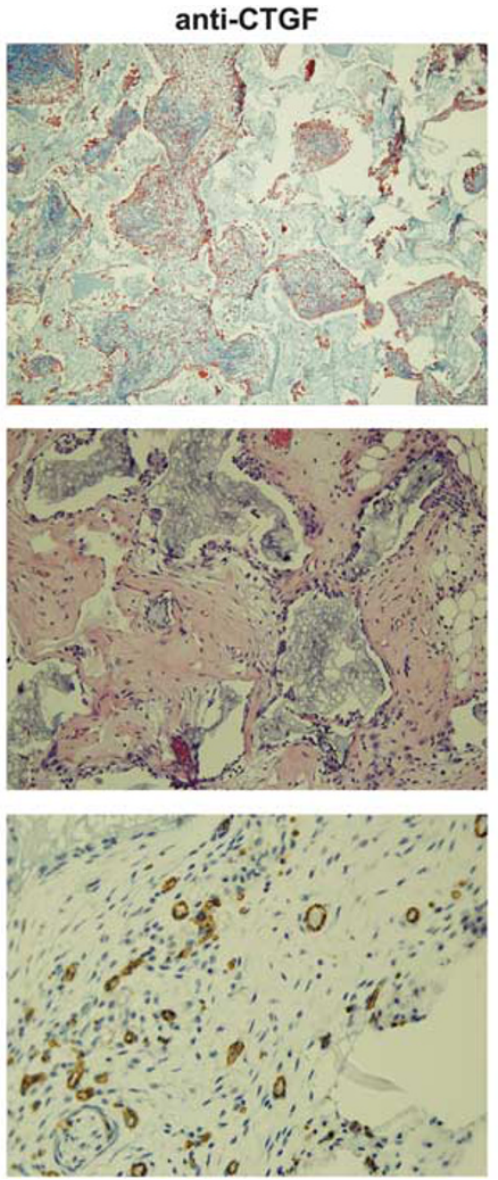
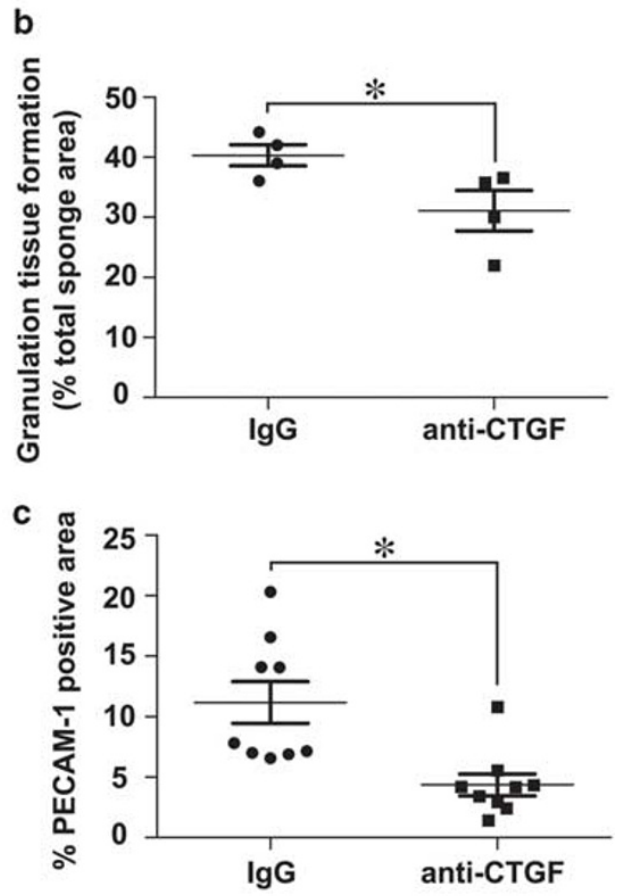

Figure 2 Connective tissue growth factor (CTGF)-blocking antibody inhibited advanced granulation tissue formation. (a) Representative low power $(\times 10)$ trichrome images showed decreased granulation tissue in anti-CTGF-treated vs IgG-treated- MSC-loaded sponges (top panel). High power $(\times 20)$ H\&E images showed that mesenchymal stem cell (MSC)-loaded sponges treated with anti-CTGF were less organized and exhibited decreased cellularity and red cell containing blood vessels as compared with IgG control (middle panels). Representative immunostained sections from anti-CTGF vs IgGtreat-sponges using anti-PECAM-1 to designate vascular density ( $\times 40$, bottom panels). (b) Graph of granulation tissue area in histological sponge sections quantified from each experimental animal presented as a percentage of total sponge area. (c) Average of the vascular density graphed as percentage of immunopositive PECAM-1 area/total tissue area in $n=10$ histological sections from each animal. Unpaired Student's $t$-test was used to compare data between groups, $n=4$ in each group. ${ }^{*} P<0.05$ designates statistical significance.

Figure 3 Addition of recombinant connective tissue growth factor (CTGF) to polyvinyl alcohol (PVA) sponges enhances a proliferative, collagenous granulation tissue. (a) Representative $\times 10$ images of trichrome-stained granulation tissue after 6 or 28 days of recombinant CTGF (rCTGF) ( $1 \mu \mathrm{g} /$ day/ sponge) or saline injections. Black $=$ sponge, blue $=$ collagen, red $=$ granulation tissue. (b) Quantitative real-time PCR analysis of mouse collagen $1 \mathrm{a} 2$ demonstrates that CTGF exposure for the initial stages (days 0-15) of wound repair yields decreased collagen deposition normalized to $18 \mathrm{~S}$ content, whereas prolonged exposure ( 28 days) increased collagen transcript levels. $n=6$ sponges per group. ${ }^{*} P<0.001$ one-way analysis of variance (ANOVA) with Bonferroni post test. (c) rCTGF addition for 28 days ( $1 \mu \mathrm{g} / \mathrm{sponge})$ increased the proliferative index of the granulation tissue as quantified by the threshold values of Ki67-positive areas in $\times 20$ representative images of PVA sponges. ANOVA ${ }^{*} P=0.0392$ vs saline. (d) CTGF was temporally regulated in murine excisional wounds ( $n=4$ animals for each time point). Murine stented excisional wounds were immunolabeled for CTGF. Representative images stained for CTGF in red and DAPI in blue demonstrate a spike in CTGF protein levels after day 4 (days 7-14). The staining was faint to absent at day 28. Both epidermal and dermal staining can be appreciated at days 7 and 14 . 
positive cells within healing areas of human burn wounds. Figure $6 \mathrm{~b}$ displays the threshold analysis estimating the total amount of CTGF signal from all the images that were in- cluded in this study. By the earliest time points in this study (the day 3-4 range) minimal to no immunoreactivity was noted in either the epidermis or scattered dermal a
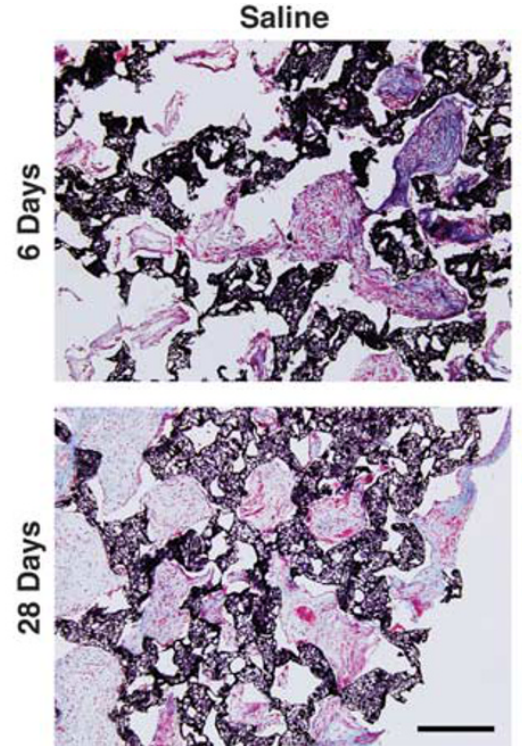

b

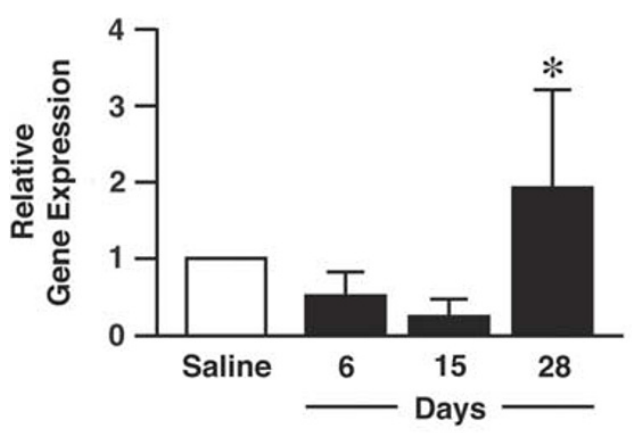

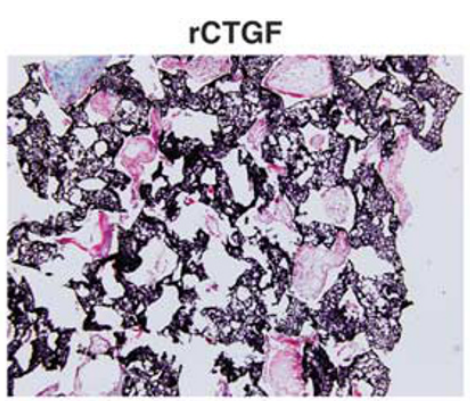

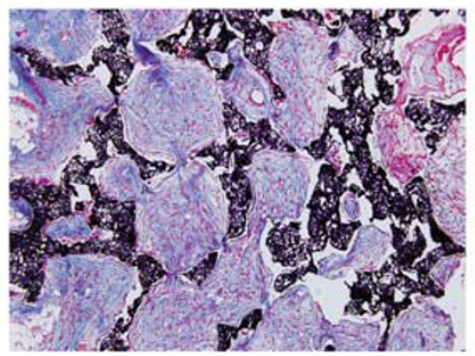

C

Proliferation

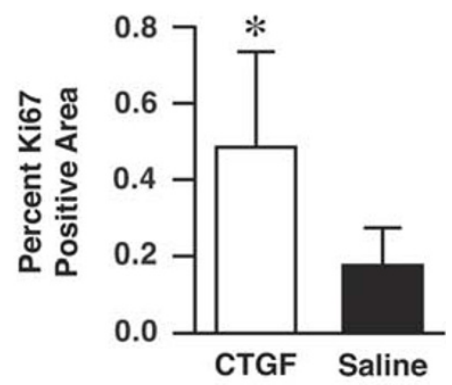

d

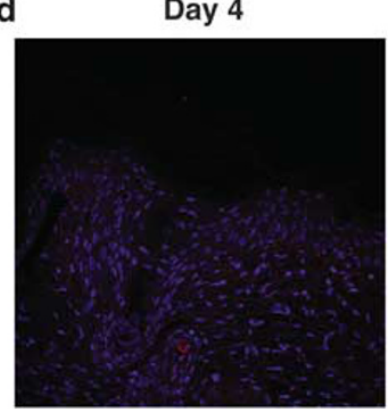

Day 14

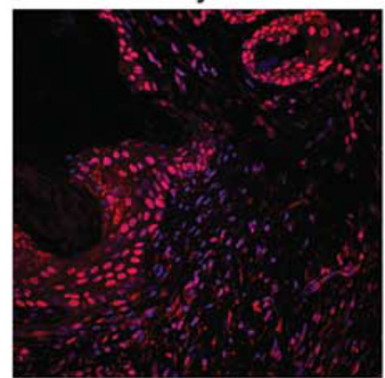

Day 7

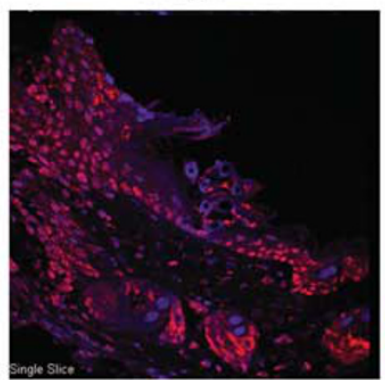

Day 28

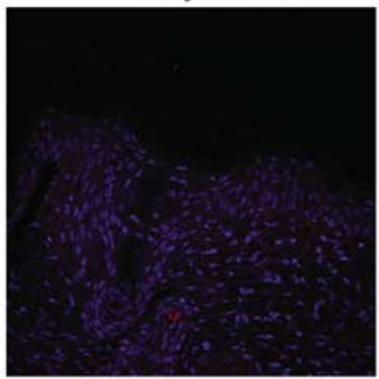



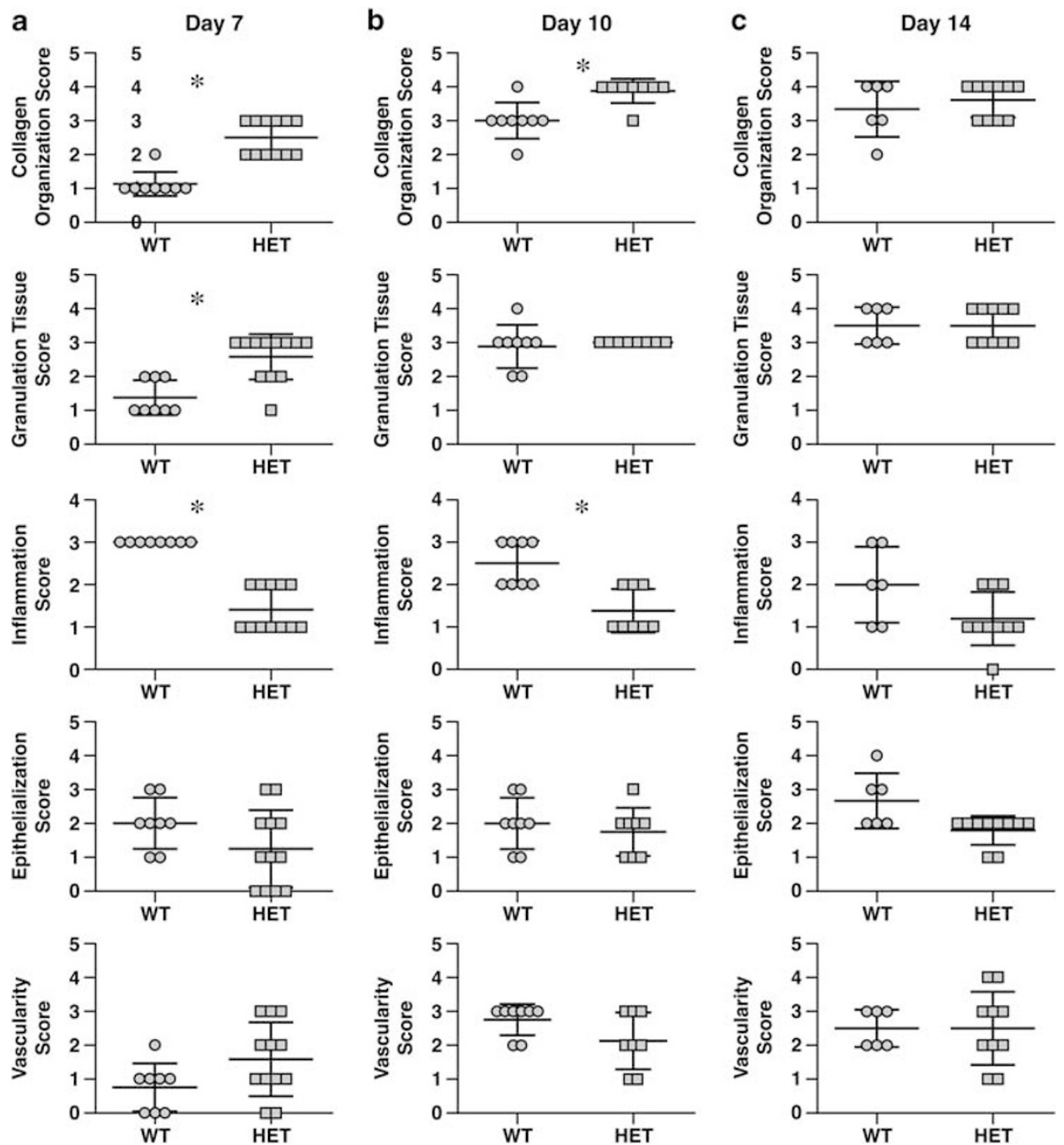

Figure $4 \mathrm{CTGF}^{\mathrm{LacZ} /+}$ mice have statistically similar wound healing parameters as WT 10 days after wounding. Histopathological scores assessing collagen content, amount of granulation tissue and vascularity within sections of excisional wounds from CTGF ${ }^{+/+}$mice $^{\text {(WT) vs CTGF }}$ LacZ/+ $^{\text {(HET) }}$ mice 7 days (a), 10 days (b) and 14 days (c) after injury. Improved collagen organization in 7- and 10-day-old wounds of HET mice was observed. $n \geq 6$ wounds per group; paired $t$-test $* P \leq 0.05$.

populations. By days 5-6, the CTGF expression modestly increased and immunoprecipitate was visible in the upper, more differentiated layers of the hypertrophic epidermis at the wound edge and in a few scattered CTGF + cells in the underlying dermis. The CTGF signal was highest at the day $7-8$ range in the healing wound areas in our sampling. Prominent CTGF immunolabeling was noted in the epidermal keratinocytes (E) within a hair follicle that was growing upward and spreading laterally to the resurface of the site of injury. An abundance of CTGF-positive dermal cells were present in the healing region of this superficial burn. By the later day 11-20 interval, the CTGF signal was once again diminished; specimens were consistently weak and diminished compared with the staining observed in the day 8 burn tissue. The dramatically decreased levels of CTGF at the later time points (days 11-20), provide evidence that CTGF levels are dynamically modulated and are rapidly attenuated in normal healing, consistent with the findings in acute mouse wounds. Pathological scarring could require the persistence or resurgence of CTGF, possibly as a result of TGF- $\beta$ signaling. Although the presence of CTGF in dermal cells was expected, the spike in CTGF in keratinocyte populations in both the differentiated cells in the interfollicular and follicular epidermis has not been previously reported.

\section{DISCUSSION}

Proteomic analysis of CM from MSCs revealed that CTGF/ CCN2 was increased in the sFRP2-expressing MSCs that previously had been shown to improve wound repair. ${ }^{3}$ Our observation of elevated CTGF in early healing contrasts the many reports that have focused on the strong association of CTGF with negative reparative sequelae such as fibrosis and impaired healing and the ongoing development of CTGF antagonists to control post-surgical scarring. ${ }^{11-13,30}$ Increased 
a
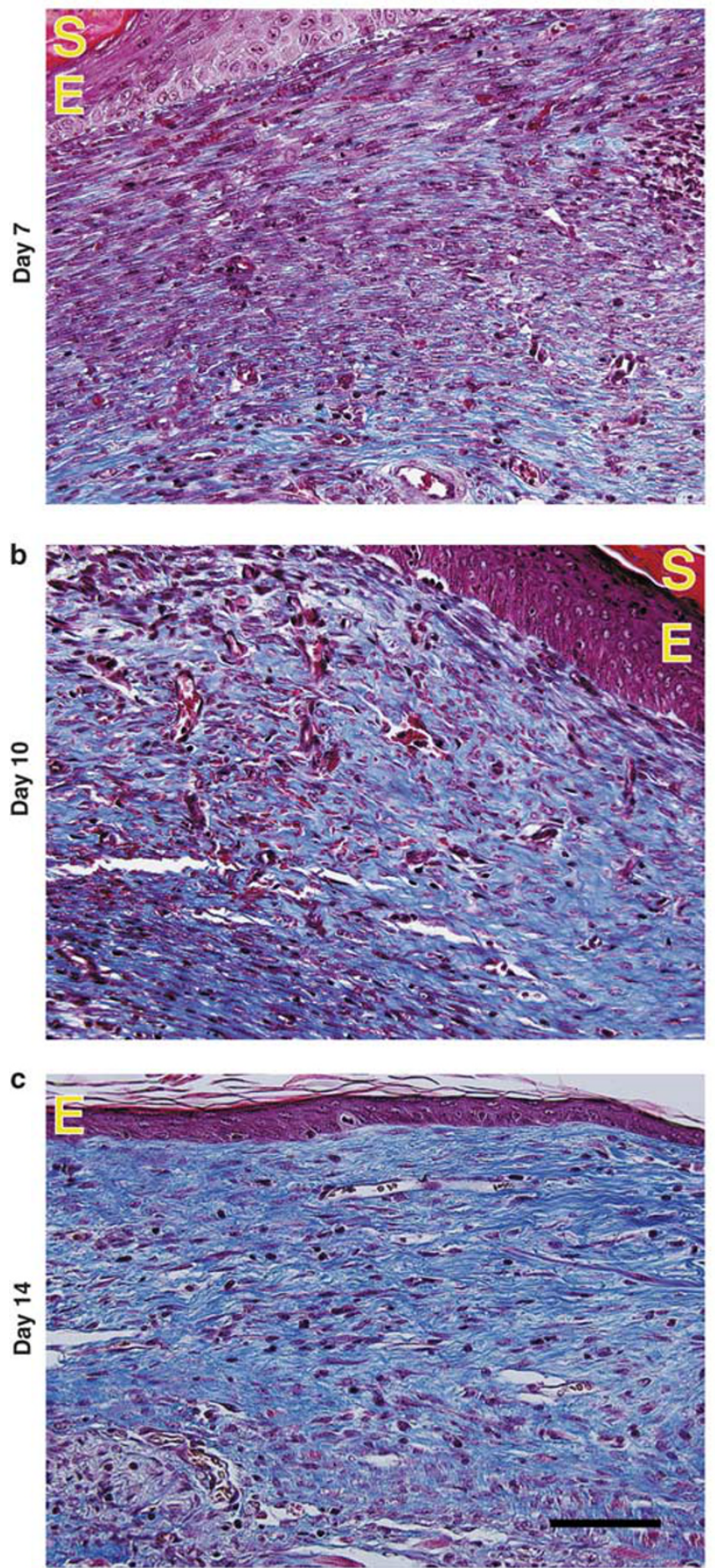
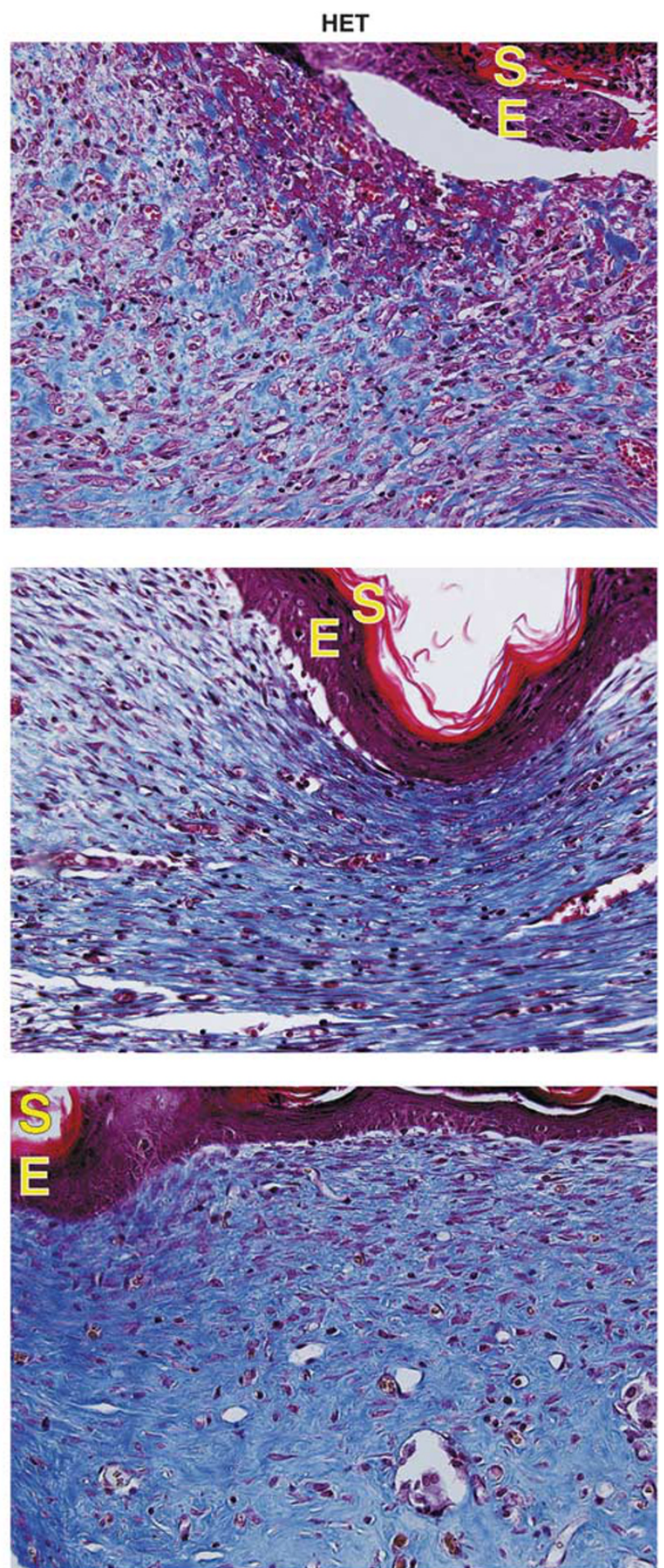

Figure 5 Connective tissue growth factor (CTGF) HET mice have no changes in wound healing. Representative $\times 40$ images of trichrome-stained excisional wounds within WT and HET mice 7 days (a) 10 days (b), and 14 days (c) post injury. Collagen is visualized by blue staining. E, epithelial layer, $\mathrm{S}$, stratum corneum buildup; dark blue signify more mature collagen, light blue signify nascent collagen fibrils.

levels of TGF- $\beta$, which is also implicated in fibrotic repair, precede CTGF induction after wounding, suggesting that CTGF is downstream of TGF- $\beta$ signaling. ${ }^{23,31}$ Although addition of CTGF alone can induce matrix deposition, several reports have reported that the fibrotic effects of CTGF are more robust if TGF- $\beta$ is present in the system. ${ }^{28,32,33}$ Indeed, others have previously reported that administration of anti-CTGF ameliorates TGF- $\beta$-induced fibrosis in mice. ${ }^{34}$ 
a

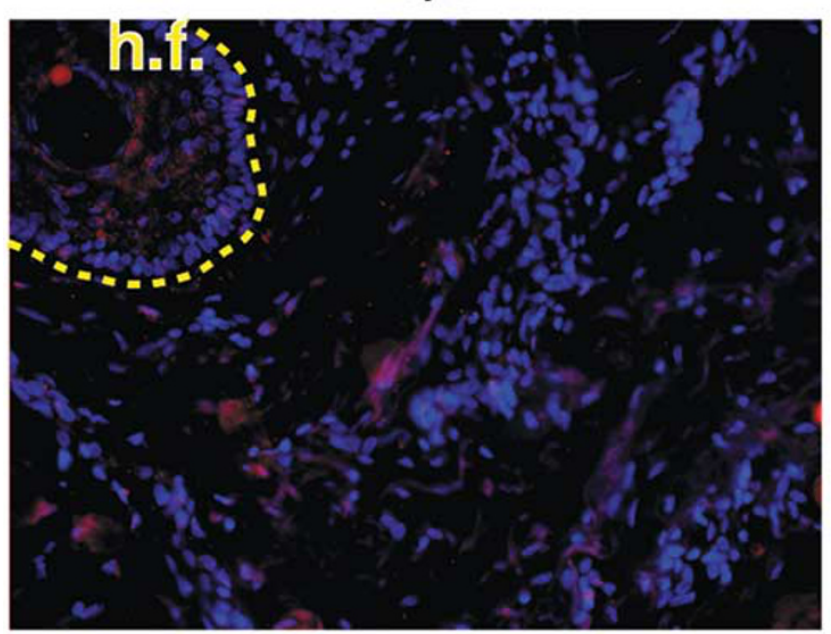

Day 8

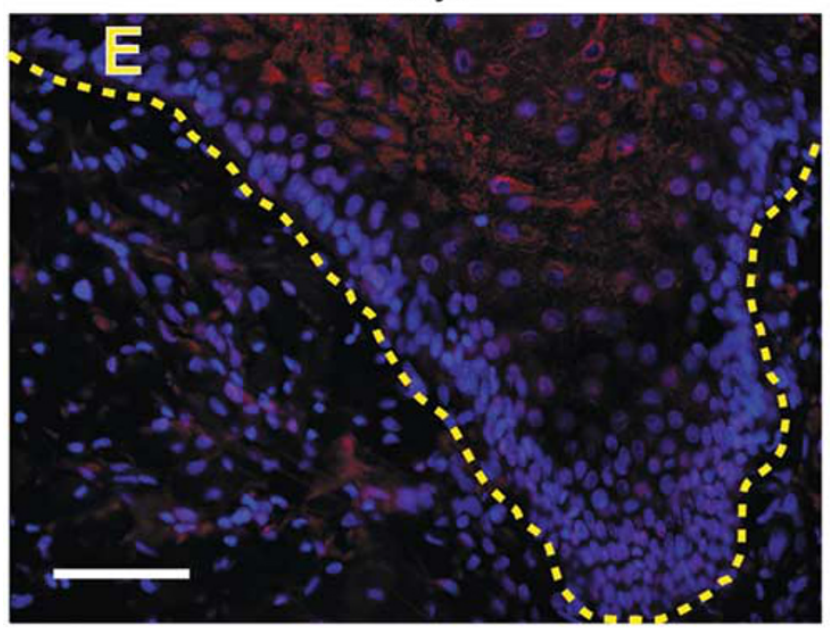

b

CTGF Immunofluorescence

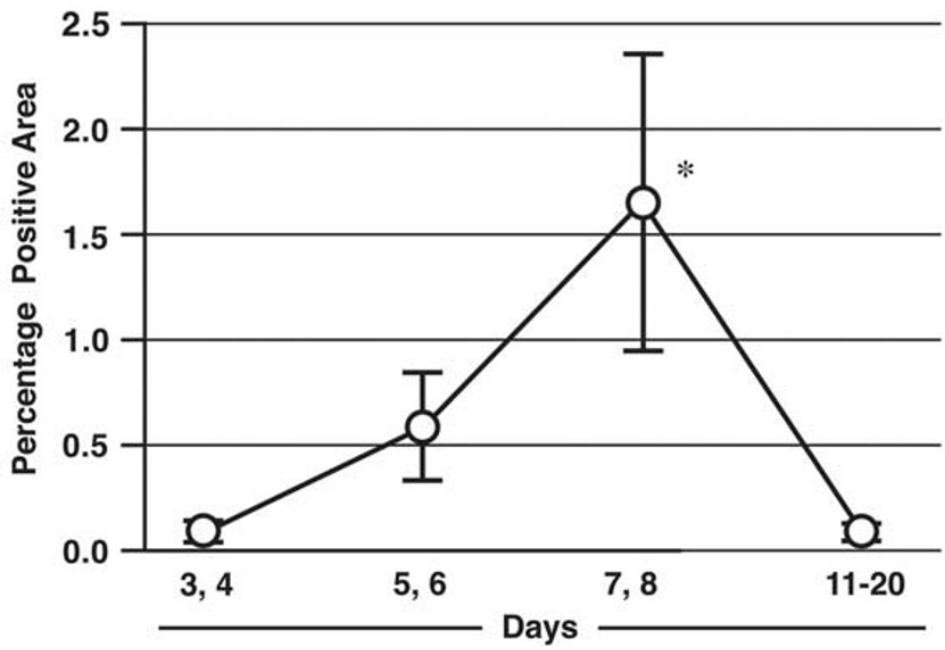

Figure 6 Connective tissue growth factor (CTGF) is temporally regulated in human burn wounds. Human burn wounds at different time points after injury were immunolabeled for CTGF. (a) Representative images of human burn wounds stained for CTGF in red and DAPI in blue demonstrate a spike in CTGF protein levels around days 7 and 8 . The dotted line indicates the dermal-epithelial interface. (b) Average percentage positive areas positive for CTGF ( \pm s.d.) as determined by thresholded images. $n \geq 4$ for each time point, ${ }^{*} P<0.001$ ANOVA with Bonferroni post test. E, epithelial layer; h.f., hair follicle. 
The results herein do not contradict the pathological role of CTGF but rather emphasize the importance of timing, duration and levels on the effects of CTGF in wound repair. This is an important point that must be considered in the design of efficacious pharmacological interventions. The PVA model of granulation tissue formation was a useful experimental tool that showed the induction of CTGF transcripts 7 days post implantation in both MSC-derived/assisted and host-derived mouse granulation tissues. This rise in transcripts preceded maximum protein levels at 15 days. The expression of CTGF declined in both MSC- and non-MSCderived (host-derived) granulation tissues by 28 days. These data illustrate the dynamic modulation of CTGF during the acute period of healing. Consistent with the descriptive data, we demonstrated that immunoinhibition of CTGF early in the process of experimental granulation tissue formation by a function-blocking antibody reduced both the quantity and quality of MSC-derived experimental granulation tissue. These data support a positive role for CTGF in early phases of the repair process.

The subcutaneous wound repair model also showed that a higher level of rCTGF at early time points had no deleterious effects on the wound process. Early, repeated CTGF administration at a nominal dose did not increase granulation tissue collagen content. Hence, early supplementation of CTGF may have a beneficial therapeutic impact in impaired wound healing by modulating tissue vascularity and matrix formation. Prolonged CTGF administration led to increased granulation tissue with much higher levels of collagen deposition (ie, fibrosis) in sponge implants. We speculate that pathological fibroblast activation is only achieved after a threshold CTGF level is reached and sustained the latter, remodeling phase of (cutaneous) repair. ${ }^{35}$

The kinetics of tissue repair include three major phases: the inflammatory, the proliferative and the remodeling/maturation. ${ }^{36}$ Our findings suggest that the early, transient upregulation of CTGF in the wound repair process promotes normal repair. Our data show physiological expression of CTGF during the proliferative phase. A similar regulation in the levels of CTGF after injury has been documented elsewhere. ${ }^{23}$ However, if CTGF levels persist during the remodeling phase of wound repair and fibrosis ensues. ${ }^{11-13}$

Previous studies have demonstrated a positive role of CTGF in the wound repair process. For example, recombinant human CTGF $\left(10-100 \mathrm{ng} / \mathrm{cm}^{2}\right)$ was added to non-human primate burn wounds for 19 days following wounding. Two weeks after CTGF administration, the wound tissue generated orderly healing fibers at the burn site, accompanied by an increased proliferative response. Compared with the control group, the CTGF-treated group had a significantly smaller wound area. ${ }^{37}$

CTGF added to MSC cultures caused a loss of expression of MSC markers, a decrease in MSC tri-lineage differentiation and an increase in collagen deposition. In vivo administration of CTGF favored fibrogenesis rather than ectopic mineralization in rodent connective tissue healing. ${ }^{27}$ These results are interesting since they demonstrate a positive role for CTGF in MSC-directed wound repair.

Our data offer further evidence that CTGF has a physiological role during cutaneous wound repair in both mice and humans. The specific role for this molecule in this setting is still unknown. However, our data hint at two possibilities: regulation of fibroblast proliferation and phenotype/differentiation as well as regulation of vascular cell populations. The differences in the amount of collagen accumulation in response to varying CTGF exposure time may be due to increased matrix production by all fibroblasts or a preferential activation of an alpha smooth muscle actin-positive myofibroblast subpopulation. ${ }^{38}$ In addition, the large decrease in vascular density observed with CTGFblocking antibody suggest that CTGF is necessary to maintain an appropriate angiogenic process within wounds. CTGF has been shown to affect endothelial cell numbers in other settings. ${ }^{29,39}$ More work on the cellular events affected by CTGF during early wound repair is necessary to fully explore the apparent bimodal activity of this molecule. There are few reports that also suggest differential effects of CTGF with different levels of expression. ${ }^{39}$ The finding that CTGF is upwardly modulated in differentiated keratinocytes in both mice and humans suggests additional roles for this molecule that extend beyond its role in fibroblast-mediated fibrosis.

This report is not the only one to document the expression of CCN family proteins in early wound repair processes. CTGF transcript levels were shown to reach the highest level of expression $2 \mathrm{~h}$ post partial hepatectomy in a murine model of liver regeneration. ${ }^{31}$ Hilfiker-Kleiner et $a l^{40}$ found that following injury, cardiomyocytes are a major source of CCN1 suggesting that CCN1, in concert with vascular endothelial growth factor and other proangiogenic factors, may be part of the paracrine program, which promotes angiogenesis in the injured heart. During cutaneous wound healing CCN family proteins were found within the granulation tissue directly expressed by fibroblasts $23,41,42$ or released from the alpha granules of platelets. ${ }^{43,44}$ In a rabbit model, it was shown that partial inhibition of CTGF did not affect wound closure or granulation tissue at late time points, ${ }^{45}$ consistent with our findings in the $\mathrm{CTGF}^{+/ \text {lacZ }}$ mouse, in which reduction in granulation tissue was observed at early time points but not at later time points. Other work suggests that CTGF is involved in pericyte adhesion and endothelial basement membrane formation during angiogenesis. ${ }^{46} \mathrm{CCN} 1$ and CCN2 support the adhesion of activated platelets through direct binding to integrin $\alpha_{\mathrm{II}} \beta_{3},{ }^{47}$ and serve as substrates to monocytes through integrin $\alpha_{\mathrm{M}} \beta_{2} \cdot{ }^{48}$ Our study suggests that the MSC secretome may stimulate favorable healing outcomes by regulating the expression of an important factor that tissue regulates repair and fibrosis. Ultimately, a better understanding of the physiological effects of CTGF in 
multiple clinical settings will help develop stage-specific strategies to augment or inhibit CTGF and thus improve healing while minimizing fibrosis.

\section{ACKNOWLEDGEMENTS}

This work was supported by NIH grants R01-HL088424, RO1-GM081635, R01-AR056138, the Department of Veterans Affairs (PPY, JMD, MG), and Vanderbilt CTSA grant 1UL1RR024975-01 from NCRR/NIH (PPY).

\section{DISCLOSURE/CONFLICT OF INTEREST}

The authors declare no conflict of interest.

1. Gnecchi M, Zhang Z, Ni A, et al. Paracrine mechanisms in adult stem cell signaling and therapy. Circ Res 2008;103:1204-1219.

2. Caplan Al, Dennis JE. Mesenchymal stem cells as trophic mediators. J Cell Biochem 2006;98:1076-1084.

3. Alfaro MP, Pagni M, Vincent A, et al. The Wnt modulator sFRP2 enhances mesenchymal stem cell engraftment, granulation tissue formation and myocardial repair. Proc Natl Acad Sci USA 2008;105: 18366-18371.

4. Mirotsou $M$, Zhang Z, Deb A, et al. Secreted frizzled related protein 2 (Sfrp2) is the key Akt-mesenchymal stem cell-released paracrine factor mediating myocardial survival and repair. Proc Natl Acad Sci USA 2007:104:1643-1648.

5. Estrada R, Li N, Sarojini $H$, et al. Secretome from mesenchymal stem cells induces angiogenesis via Cyr61. J Cell Physiol 2009;219:563-571.

6. Salasznyk RM, Westcott AM, Klees RF, et al. Comparing the protein expression profiles of human mesenchymal stem cells and human osteoblasts using gene ontologies. Stem Cells Dev 2005;14:354-366.

7. Polacek M, Bruun JA, Elvenes J, et al. The secretory profiles of cultured human articular chondrocytes and mesenchymal stem cells: implications for autologous cell transplantation strategies. Cell Transplant 2010:20:1381-1393.

8. Shi-Wen X, Leask A, Abraham D. Regulation and function of connective tissue growth factor/CCN2 in tissue repair, scarring and fibrosis. Cytokine Growth Factor Rev 2008;19:133-144.

9. Rachfal AW, Brigstock DR. Structural and functional properties of CCN proteins. Vitam Horm 2005;70:69-103.

10. Chen CC, Lau LF. Functions and mechanisms of action of CCN matricellular proteins. Int J Biochem Cell Biol 2010;41:771-783.

11. Ito $\mathrm{Y}$, Aten J, Bende RJ, et al. Expression of connective tissue growth factor in human renal fibrosis. Kidney Int 1998;53:853-861.

12. di Mola FF, Friess $\mathrm{H}$, Martignoni ME, et al. Connective tissue growth factor is a regulator for fibrosis in human chronic pancreatitis. Ann Surg 1999;230:63-71.

13. Igarashi A, Nashiro K, Kikuchi K, et al. Connective tissue growth factor gene expression in tissue sections from localized scleroderma, keloid and other fibrotic skin disorders. J Invest Dermatol 1996:106:729-733.

14. Crawford LA, Guney MA, Oh YA, et al. Connective tissue growth factor (CTGF) inactivation leads to defects in islet cell lineage allocation and beta-cell proliferation during embryogenesis. Mol Endocrinol 2009:23:324-336.

15. Subramaniam M, Saffaripour S, Van De Water $L$, et al. Role of endothelial selectins in wound repair. Am J Pathol 1997;150: 1701-1709.

16. Shi $Y$, Reitmaier $B$, Regenbogen J, et al. CARP, a cardiac ankyrin repeat protein, is up-regulated during wound healing and induces angiogenesis in experimental granulation tissue. Am J Pathol 2005;166:303-312.

17. Tropel $P, N o e ̈ l ~ D, ~ P l a t e t ~ N$, et al. Isolation and characterisation of mesenchymal stem cells from adult mouse bone marrow. Exp Cell Res 2004:295:395-406.

18. Higdon R, Hogan JM, Van Belle $G$, et al. Randomized sequence databases for tandem mass spectrometry peptide and protein identification. OMICS 2005;9:364-379.

19. Elias JE, Haas W, Faherty BK, et al. Comparative evaluation of mass spectrometry platforms used in large-scale proteomics investigations. Nat Methods 2005;2:667-675.
20. Tabb DL, Friedman DB, Ham AJ. Verification of automated peptide identifications from proteomic tandem mass spectra. Nat Protoc 2006; 1:2213-2222.

21. Ma ZQ, Dasari S, Chambers MC, et al. IDPicker 2.0: improved protein assembly with high discrimination peptide identification filtering. J Proteome Res 2009;8:3872-3881.

22. Alfaro MP, Vincent A, Saraswati $S$, et al. sFRP2 suppression of bone morphogenic protein (BMP) and Wnt signaling mediates mesenchymal stem cell (MSC) self-renewal promoting engraftment and myocardial repair. J Biol Chem 2010;285:35645-35653.

23. Igarashi A, Okochi H, Bradham DM, et al. Regulation of connective tissue growth factor gene expression in human skin fibroblasts and during wound repair. Mol Biol Cell 1993;4:637-645.

24. Leask A, Abraham DJ. The role of connective tissue growth factor, a multifunctional matricellular protein, in fibroblast biology. Biochem Cell Biol 2003;81:355-363.

25. Krummel TM, Michna BA, Thomas BL, et al. Transforming growth factor beta (TGF-beta) induces fibrosis in a fetal wound model. J Pediatr Surg 1988;23:647-652.

26. Cooney R, locono J, Maish $\mathrm{G}$, et al. Tumor necrosis factor mediates impaired wound healing in chronic abdominal sepsis. J Trauma 1997;42:415-420.

27. Lee $\mathrm{CH}$, Shah B, Moioli EK, et al. CTGF directs fibroblast differentiation from human mesenchymal stem/stromal cells and defines connective tissue healing in a rodent injury model. J Clin Invest 2010;120: 3340-3349.

28. Frazier K, Williams $\mathrm{S}$, Kothapalli $\mathrm{D}$, et al. Stimulation of fibroblast cell growth, matrix production, and granulation tissue formation by connective tissue growth factor. J Invest Dermatol 1996;107:404-411.

29. Ivkovic S, Yoon BS, Popoff SN, et al. Connective tissue growth factor coordinates chondrogenesis and angiogenesis during skeletal development. Development 2003;130:2779-2791.

30. Liu S, Shi-wen X, Abraham DJ, et al. CCN2 is required for bleomycininduced skin fibrosis in mice. Arthritis Rheum 2011;63:239-246.

31. Ujike K, Shinji T, Hirasaki S, et al. Kinetics of expression of connective tissue growth factor gene during liver regeneration after partial hepatectomy and D-galactosamine-induced liver injury in rats. Biochem Biophys Res Commun 2000;277:448-454.

32. Mori T, Kawara S, Shinozaki M, et al. Role and interaction of connective tissue growth factor with transforming growth factor-beta in persistent fibrosis: a mouse fibrosis model. J Cell Physiol 1999;181: 153-159.

33. Bonniaud $\mathrm{P}$, Margetts $\mathrm{PJ}, \mathrm{Kolb} \mathrm{M}$, et al. Adenoviral gene transfer of connective tissue growth factor in the lung induces transient fibrosis. Am J Respir Crit Care Med 2003;168:770-778.

34. Ikawa $\mathrm{Y}, \mathrm{Ng} \mathrm{PS}$, Endo $\mathrm{K}$, et al. Neutralizing monoclonal antibody to human connective tissue growth factor ameliorates transforming growth factor-beta-induced mouse fibrosis. J Cell Physiol 2008;216:680-687.

35. Chen $Y$, Shi-Wen $X$, van Beek J, et al. Matrix contraction by dermal fibroblasts requires transforming growth factor-beta/activin-linked kinase 5, heparan sulfate-containing proteoglycans, and MEK/ERK: insights into pathological scarring in chronic fibrotic disease. Am J Pathol 2005;167:1699-1711.

36. Arnold F, West DC. Angiogenesis in wound healing. Pharmacol Ther 1991;52:407-422.

37. Liu LD, Shi HJ, Jiang $L$, et al. The repairing effect of a recombinant human connective-tissue growth factor in a burn-wounded rhesusmonkey (Macaca mulatta) model. Biotechnol Appl Biochem 2007:47 (Pt 2):105-112.

38. Darby I, Skalli O, Gabbiani G. Alpha-smooth muscle actin is transiently expressed by myofibroblasts during experimental wound healing. Lab Invest 1990;63:21-29.

39. Guney MA, Petersen CP, Boustani $A$, et al. Connective tissue growth factor acts within both endothelial cells and $\beta$ cells to promote proliferation of developing $\beta$ cells. Proc Natl Acad Sci 2011;108: 15242-15247.

40. Hilfiker-Kleiner D, Kaminski K, Kaminska A, et al. Regulation of proangiogenic factor CCN1 in cardiac muscle. Circulation 2004;109: 2227-2233.

41. Chen CC, Chen N, Lau LF. The angiogenic factors Cyr61 and connective tissue growth factor induce adhesive signaling in primary human skin fibroblasts. J Biol Chem 2001;276:10443-10452. 
42. Lin YT, Tang $\mathrm{CH}$, Chuang WJ, et al. Inhibition of adipogenesis by RGDdependent disintegrin. Biochem Pharmacol 2005;70:1469-1478.

43. Kubota S, Takigawa M. CCN family proteins and angiogenesis: from embryo to adulthood. Angiogenesis 2007;10:1-11.

44. Cicha I, Garlichs CD, Daniel WG, et al. Activated human platelets release connective tissue growth factor. Thromb Haemost 2004;91: 636-847.

45. Sisco M, Kryger ZB, O'Shaughnessy KD, et al. Antisense inhibition of connective tissue growth factor (CTGF/CCN2) mRNA limits hypertrophic scarring without affecting wound healing in vivo. Wound Rep Reg 2008;16:661-673.
46. Hall-Glenn F, De Young RA, Huang B. CCN2/Connective tissue growth factor is essential for pericyte adhesion and endothelial basement membrane formation during angiogenesis. PLoS One 2011;7:e30562.

47. Jedsaydayanmata A, Lau LF, Chen CC, et al. Activation-dependent adhesion of human platelets to Cyr61 and Fisp12/mouse connective tissue growth factor is mediated through integrin alpha(Illb)beta(3). J Biol Chem 1999;274:24321-24327.

48. Schober JM, Chen N, Grzeszkiewicz TM, et al. Identification of integrin $\alpha \mathrm{M} \beta 2$ as an adhesion receptor on peripheral blood monocytes for Cyr61 (CCN1) and connective tissue growth factor (CCN2): immediate-early gene products expressed in atherosclerotic lesions. Blood 2002;99:4457-4465. 